\title{
Analgesia after upper abdominal surgery with extradural buprenorphine with lidocaine
}

\author{
Zen'ichiro Wajima MD PhD, * \\ Toshiro Shitara MD PhD, ${ }^{\dagger}$ \\ Gen Ishikawa MD PhD, \\ Tetsuo Inoue MD PhD, * \\ Ryo Ogawa MD $\mathrm{PhD}^{\dagger}$
}

Purpose: To determine whether the continuous low thoracic extradural administration of the same dose of lidocaine at low concentration with a high infusion rate or at high concentration with a low infusion rate in combination with a fixed dose of buprenorphine $\left(0.4 \mathrm{mg} \cdot \mathrm{day}^{-1}\right)$ modifies postoperative pain relief.

Methods: Twenty-eight patients undergoing elective upper abdominal surgery were randomly allocated to one of two groups to receive lidocaine $2 \%$ - buprenorphine at a rate of $6.3 \mathrm{ml} \cdot \mathrm{hr}^{-1}(2 \%$ group, $n=13)$ or lidocaine $6 \%$ - buprenorphine at a rate of $2.1 \mathrm{ml} \cdot \mathrm{hr} r^{-1}(6 \%$ group, $n=15)$. During suture of the peritoneum, mepivacaine $2 \%(8 \mathrm{ml})$ with $0.1 \mathrm{mg}(0.5 \mathrm{ml})$ buprenorphine was infused extradurally. After extubation, the continuous extradural infusion was initiated. Patients were assessed for the level of analgesia with the $10 \mathrm{~cm}$ VAS score at rest and with the Prince Henry Pain Scale (PHPS) at 3, 6, 9, 12, 18, and 24 hr postoperatively.

Results: The visual analogue scale (VAS) scores at rest did not differ between the two groups except at $18 \mathrm{hr}$ after surgery. The Prince Henry Pain Scale (PHPS) scores were not different between the two groups postoperatively.

Conclusion: There was no difference in analgesia produced by the continuous extradural infusion of lidocaine $2 \%$ - buprenorphine at a rate of $6.3 \mathrm{ml} \cdot \mathrm{hr}^{-1}$ and that of lidocaine $6 \%$ - buprenorphine at a rate of $2.1 \mathrm{ml} \cdot \mathrm{hr}^{-1}$ following upper abdominal surgery.

Objectif : Déterminer si la perfusion épidurale thoracique basse d'une même dose de lidocaine à basse concentration avec un débit élevé de perfusion ou une haute concentration avec un débit faible de perfusion en association avec une dose fixe de buprénorphine $\left(0,4 \mathrm{mg}^{-1}\right)$ modifie le soulagement de la douleur.

Méthodes : Vingt-huit patients programmés pour une chirurgie non urgente de l'étage supérieur de l'abdomen participaient à l'étude. Ils étaient répartis aléatoirement en deux groupes dont l'un recevait lidocaine $2 \%$ buprénorphine à la vitesse de $6,3 \mathrm{ml} \cdot \mathrm{h}^{-1}$ (groupe $2 \%=13$ ) l'autre lidocaine $6 \%$ - buprénorphine (groupe $6 \%$ $=15$ ) à la vitesse de $2,1 \mathrm{ml} \cdot \mathrm{h}^{-1}$. Au moment de la fermeture du péritoine, on injectait en épidural de la mépivacaîne à $2 \%(8 \mathrm{ml})$ avec $0,1 \mathrm{mg}(0,5)$ de buprénorphine. Après l'extubation, on débutait la perfusion épidurale continue. Le niveau d'analgésie des patients était évalué à 3,6, 9, 12, 18 et 24 heures en post-opératoire au moyen de l'EVA de $10 \mathrm{~cm}$ pour la douleur au repos et avec le Prince Henry Pain Scale (PHPS).

Résultats : Les scores sur l'ÉVA au repos ne différaient pas entre les groupes excepté 18 hres après l'intervention. Le PHPS r'était différent en aucun moment de la période postopératoire

Conclusion : Après une chirurgie abdominale, l'analgésie produite par la perfusion épidurale de lidocaïne $2 \%$ buprénorphine au débit de $6,3 \mathrm{ml} \cdot \mathrm{h}^{-1}$ était la même que celle produite par la lidocaine $6 \%$ - buprénorphine au débit de $2,1 \mathrm{ml} \cdot \mathrm{h}^{-1}$.

\footnotetext{
*From the Department of Anaesthesia, Chiba Hokusoh Hospital, Nippon Medical School, 1715, Kamagari, Inba-mura, Inba-gun, Chiba 270-16, Japan and tDepartments of Anaesthesiology and Intensive Care Medicine, Nippon Medical School, 11-5, Sendagi, Bunkyo-ku, Tokyo 113, Japan. Address correspondence to: Zen'ichiro Wajima MD PhD; Phone: +81-476-99-1111 ext: 5750; Fax: +81-476-99- 1843 Accepted for publication October 3, 1997.
} 
I $\mathrm{N}$ recent years, the use of a continuous extradural injection of local anaesthetic-opioid has become common for the management of postoperative pain because local anaesthetics and opioids are believed to act synergistically when given extradurally. ${ }^{1-5}$ Although it has been a matter of debate as to whether the efficacy of a local anaesthetic agent for extradural analgesia depends on the volume of local anaesthetic or the dose of the agent, it is now considered that the efficacy of a local anaesthetic for extradural analgesia is dose-dependent. The present study was designed to determine whether the continuous extradural administrations of the same dose of lidocaine at a low concentration with a high infusion rate or at a high concentration with a low infusion rate in combination with a fixed dose of buprenorphine could provide similar postoperative pain relief.

\section{Methods}

A randomised prospective study was undertaken in 28 adult ASA class I or II patients scheduled to undergo elective upper abdominal surgery (open gastrectomy or open cholecystectomy), with the approval of the Ethics Committee and the written informed consent of the patients. Patients receiving hypertensive or analgesic medication in the preoperative period, or with renal or hepatic dysfunction were excluded. Surgery of all 28 patients was performed by the same surgeon.

Two days before surgery and before premedication for surgery, all patients were instructed in the use of the $10-\mathrm{cm}$ visual analogue scale (VAS) scores $^{6,7}$ ranging from "no pain" to "unbearable pain." Patients were premedicated with $0.5 \mathrm{mg}$ atropine sulfate $i m$ and 50 mg hydroxyzine $\mathrm{HCl} i m, 30 \mathrm{~min}$ before they entered the operation room. An extradural catheter was inserted through a 17-gauge Tuohy needle placed at the $\mathrm{T}_{9-10}$ or $\mathrm{T}_{10-11}$ interspace and passed about $4 \mathrm{~cm}$ cephaladly. The extradural space was identified by the loss-ofresistance technique using physiological saline. Preoperative extradural analgesia was obtained with about $15 \mathrm{ml}$ mepivacaine $2 \%$ with additional doses of about $8 \mathrm{ml}$ mepivacaine $2 \%$ every $45 \mathrm{~min}$ during surgery. After the initial analgesia reached $\mathrm{T}_{4}-\mathrm{L}_{1}$, general anaesthesia was induced with $5 \mathrm{mg} \cdot \mathrm{kg}^{-1}$ thiopentone and muscle relaxant with $0.1 \mathrm{mg} \cdot \mathrm{kg}^{-1}$ vecuronium. Anaesthesia was maintained with extradural anaesthesia and $\mathrm{N}_{2} \mathrm{O}-\mathrm{O}_{2}$-isoflurane $0.5-1 \%$. No supplemental analgesics were administered during the surgery. During the suture of the peritoneum, $8 \mathrm{ml}$ mepivacaine $2 \%$ with 0.1 $\mathrm{mg}(0.5 \mathrm{ml})$ buprenorphine was infused extradurally.

The patients were randomly assigned to receive either continuous extradural lidocaine 2\%-buprenorphine ( $2 \%$ group) or continuous extradural lidocaine $6 \%$-buprenorphine (6\% group) for postoperative anal- gesia. After extubation, a continuous extradural infusion was initiated using a standardised syringe pump (model STC-525, Terumo, Tokyo). Patients in the $2 \%$ group $(n=13)$ received an extradural infusion at 6.3 $\mathrm{ml} \cdot \mathrm{hr}^{-1}$ of lidocaine $2 \%$ - buprenorphine solution, which consisted of $30 \mathrm{ml}$ lidocaine $10 \%, 25 \mathrm{ml}$ distilled water, $93 \mathrm{ml}$ physiological saline and $0.4 \mathrm{mg}(2 \mathrm{ml})$ buprenorphine. The osmotic pressure was $327 \mathrm{mOsm} \cdot \mathrm{l}^{-1}$. Patients in the $6 \%$ group $(n=15)$ received an extradural infusion at $2.1 \mathrm{ml} \cdot \mathrm{hr}^{-1}$ of lidocaine 6\%-buprenorphine solution, which consisted of $30 \mathrm{ml}$ lidocaine $10 \%, 18 \mathrm{ml}$ distilled water and $0.4 \mathrm{mg}(2 \mathrm{ml})$ buprenorphine. The osmotic pressure was $423 \mathrm{mOsm} \cdot \mathrm{l}^{-1}$.

Patients were assessed for the level of analgesia with the $10 \mathrm{~cm}$ VAS score at rest and with the Prince Henry Pain Scale (PHPS $)^{8}(0$, no pain on coughing; 1 , pain on coughing but not on deep breathing; 2, pain on deep breathing but not at rest; 3 , pain at rest, slight; 4 , pain at rest, severe), at $3,6,9,12,18$, and $24 \mathrm{hr}$ postoperatively. The pain assessors were blinded as to which solution had been used. Systolic and diastolic arterial blood pressure, heart rate, respiratory rate, and the presence of adverse side effects such as nausea and dizziness were recorded during the first $24 \mathrm{hr}$ every one hour. Arterial blood pressure and heart rate were measured on admission as the control values. Venous samples for the analysis of plasma lidocaine concentrations were taken at 16 and $23 \mathrm{hr}$ postoperatively. The plasma lidocaine concentrations were measured by a fluorescence polarisation immunoassay. ${ }^{9}$ During the postoperative period, supplemental analgesia (pentazocine $15 \mathrm{mg} \mathrm{im}$ ) was available as needed for each patient to establish comfort at rest.

Fisher's exact probability test was used to compare the sex ratio distributions and the type of surgery distribution between the two groups. Differences in age, weight, height, duration of surgery, VAS scores, PHPS scores and the dose of supplemental opioid requirements between the two groups were assessed by the Mann-Whitney Utest. Differences in plasma lidocaine levels were assessed by one-way ANOVA and Scheffé's test for post hoc testing. The time to first analgesic administration (pentazocine $15 \mathrm{mg}$ ) was studied using a survival analysis which included the generalised Wilcoxon test and Cox-Mantel test. Intragroup comparisons of systolic arterial pressure and diastolic arterial pressure were performed by repeatedmeasures two-way ANOVA with Dunnett's procedure as a post hoc test. Between-group comparisons were made at each time point using the unpaired $t$ test. $P<0.05$ was considered statistically significant.

\section{Results}

There were 13 patients assigned to the $2 \%$ group and 15 to the $6 \%$ group. There were no differences in the demographic or clinical data of the patients (Table I). The VAS 
TABLE I Demographic and clinical data of patients undergoing upper abdominal surgery (Values are mean \pm SD [range]).

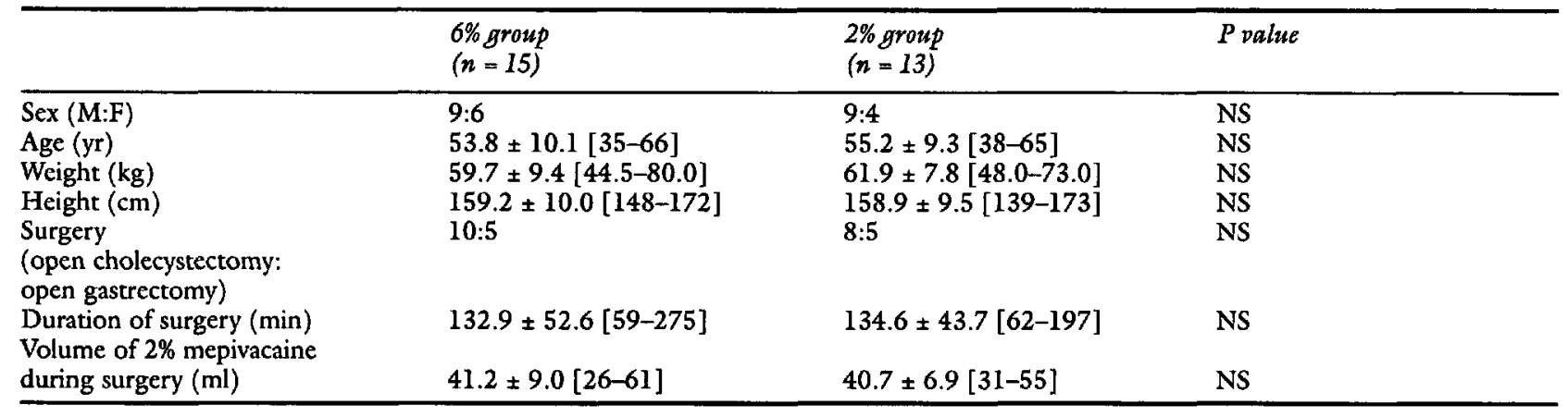

NS = not significant

scores were not different between the two groups except at $18 \mathrm{hr}$ postoperatively, when the pain scores were greater in the $6 \%$ group than in the $2 \%$ group (Figure 1 ). The PHPS scores after surgery were not different between the two groups (Figure 2). Figure 3 shows the times to the first pentazocine administration $i m$ as supplementary analgesia using survival analysis. The times did not differ between the two groups. There was no difference between the two groups in either the number of the patients requiring supplemental opioid (pentazocine) or the dose of pentazocine (Table II). There was a difference between the plasma lidocaine concentrations at the 16th and $23 \mathrm{rd}$ hr postoperation in the $2 \%$ group, and a difference between the concentration at the 23rd hr postoperation in the $2 \%$ group and that at the 16 th $\mathrm{hr}$ postoperation in the $6 \%$ group (Figure 4 ). There were no differences in systolic or diastolic arterial pressure between the two groups at any time. At three hours postoperatively, the systolic arterial blood pressure values were higher than the control values obtained on admission in the $6 \%$ group. At nine hours postoperatively, the diastolic arterial blood pressures were lower than the control values in the $6 \%$ group.

Side effects were observed in two patients in the $2 \%$ group, who complained of nausea, and in two patients in the $6 \%$ group, who complained of nausea oar dizziness. Respiratory depression (ventilators frequency $<8$ b.p.m.) did not occur. No subjective side effects due to possible lidocaine overdose were shown.

TABLE II Patient numbers and the total doses of supplemental narcotic requirements (pentazocine)

\begin{tabular}{llll}
\hline & $6 \%$ group & $2 \%$ group & P palue \\
\hline $\begin{array}{l}\text { Number of patients requiring } \\
\text { supplemental opioid pentazocine) }\end{array}$ & $(\mathrm{n}=15)$ & $(\mathrm{n}=13)$ \\
$(0 \mathrm{mg} / 15 \mathrm{mg} / 30 \mathrm{mg} / 45 \mathrm{mg})$ & & $10 / 1 / 0 / 2 \mathrm{NS}$ \\
\hline
\end{tabular}

NS = not significant

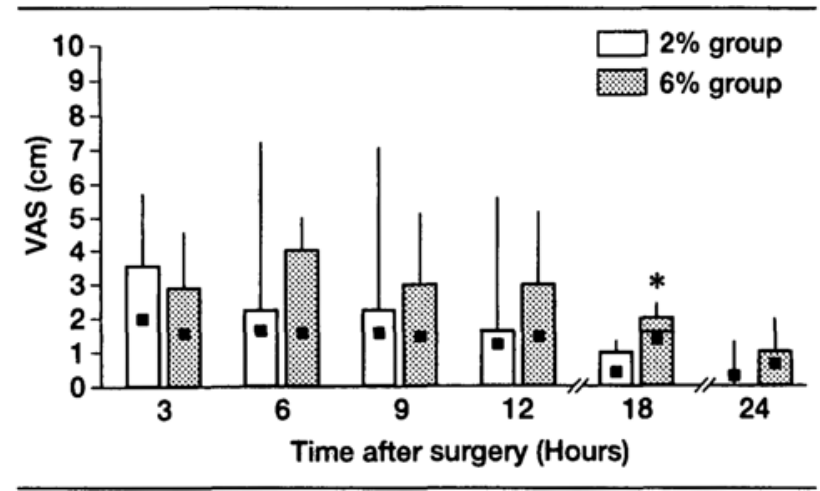

FIGURE 1 Visual analogue scale (VAS) scores at each time after surgery in the $2 \%$ and $6 \%$ groups. The upper border of each box show the 75th percentile. The horizontal line within the box shows the median, marking the 50th percentile. The rectangular symbols in the box or near each show the mean. The vertical error bars show the 90 th percentile. ${ }^{*} P<0.05$.

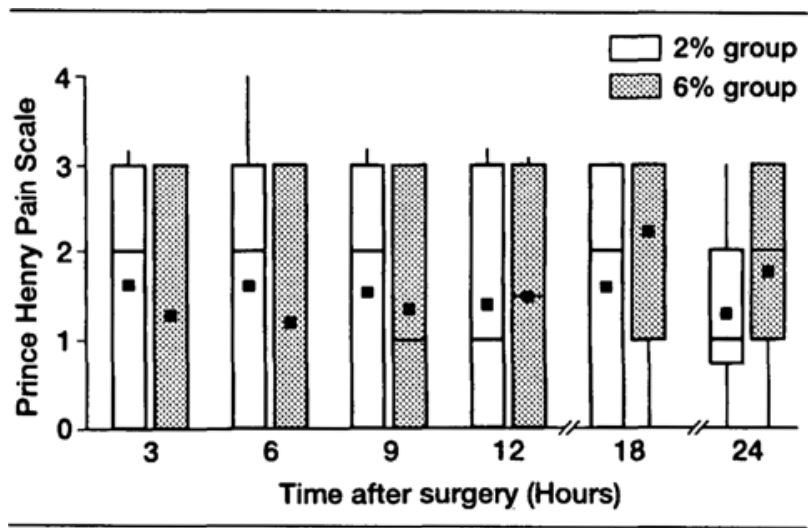

FIGURE 2 Prince Henry Pain Scale (PHPS) scores at the indicated times after surgery in the $2 \%$ and $6 \%$ groups. The lower and upper borders of each box show the 25 th and 75 th percentiles, respectively. The horizontal line within each box shows the median, marking the 50th percentile. The rectangular symbols in the box show the mean. The vertical error bars show the 10th and 90th percentiles, respectively. 


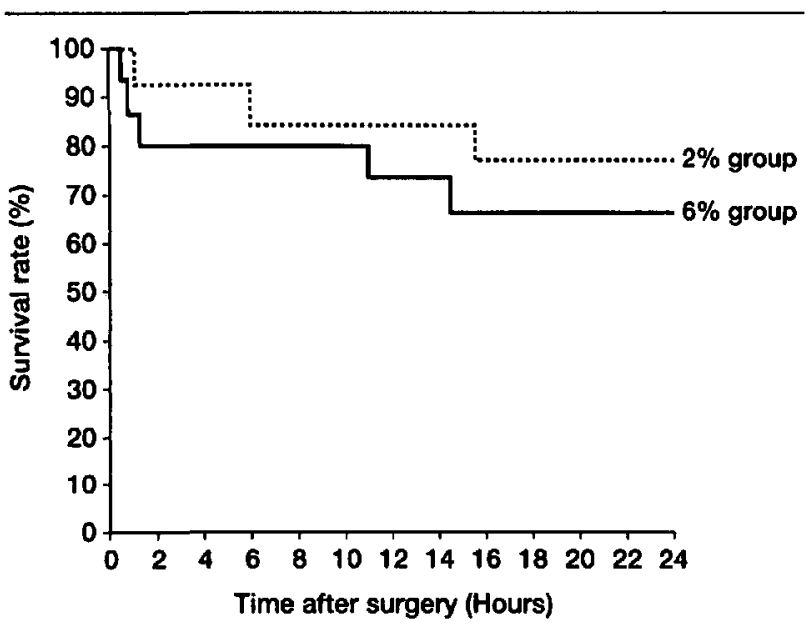

FIGURE 3 Time to first $i m$ pentazocine administration as supplementary analgesia calculated using survival analysis for the $2 \%$ group $(--)$ and $6 \%$ group $(-)$. The time to first analgesic use was similar in the two groups.

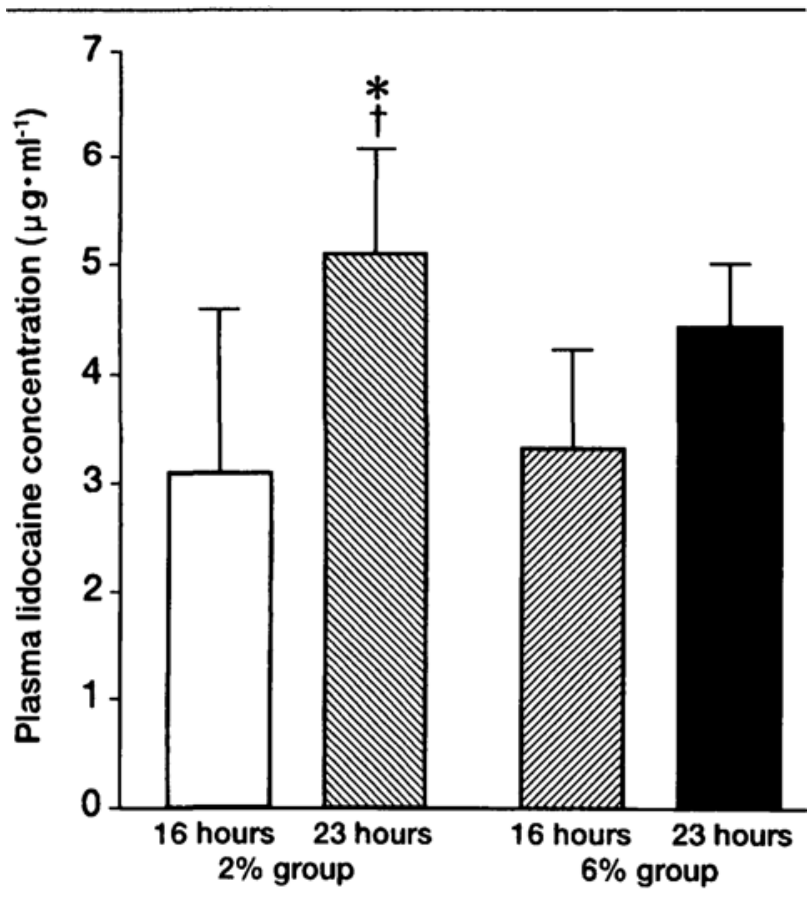

FIGURE 4 Plasma lidocaine concentrations at the 16th and 23rd hours postoperation in the $2 \%$ group and $6 \%$ group (mean $\pm S D$ ). $\square=$ Plasma lidocaine concentration at the 16 th postoperative hour of the $2 \%$ group $(n=10)$. $\$$ = Plasma lidocaine concentration at the 23 rd postoperative hour of the $2 \%$ group $(n=12)$. - Plasma lidocaine concentration at the 16th postoperative hour of the $6 \%$ group $(n=10) . \square=$ Plasma lidocaine concentration at the 23 rd postoperative hour of the $6 \%$ group $(n=8) .{ }^{*} P<0.05$ compared with the concentration 16 hours postoperatively in the $2 \%$ group; ${ }^{t} P<0.05$ compared with the concentration 16 hours postoperatively in the $6 \%$ group.

\section{Discussion}

Our recent study ${ }^{10}$ was designed to determine. whether a high-rate continuous administration of extradural analgesics (lidocaine and buprenorphine) could provide good postoperative pain relief compared with a low-rate infusion in combination with a fixed dose of buprenorphine (0.4 mg.day $\left.{ }^{-1}\right)$. Patients undergoing elective upper abdominal surgery were randomly assigned to one of two groups to receive lidocaine 2\%-buprenorphine at either a low rate, $2.1 \mathrm{ml} \cdot \mathrm{hr}^{-1}$ (low rate group) or a high rate, $6.3 \mathrm{ml} \cdot \mathrm{hr}^{-1}$ (high rate group). Between the 6th to 24th hours postoperation, the VAS scores at rest were higher in the low rate group than in the high rate group. At the 6 th, 9 th 12 th and 24 th postoperative hours, the PHPS scores were higher in the low rate group than in the high rate group. We concluded that when added to a fixed dose of buprenorphine, the continuous extradural infusion of lidocaine 2\%-buprenorphine at a high rate was more effective than that at a low rate for postoperative analgesia, and that it was safe at least up to $24 \mathrm{hr}$ postoperation. The present study was designed to determine which was more effective for postoperative pain relief after upper abdominal surgery: lidocaine $2 \%$-buprenorphine at a rate of $6.3 \mathrm{ml} \cdot \mathrm{hr}^{-1}$ or lidocaine $6 \%$-buprenorphine at a rate of $2.1 \mathrm{ml} \cdot \mathrm{hr}^{-1}$ in combination with a fixed dose of buprenorphine. In both groups, lidocaine was administered extradurally at $126 \mathrm{mg} \cdot \mathrm{hr}^{-1}$. We conclude that there was no difference between the continuous extradural infusion of lidocaine $2 \%$-buprenorphine at a rate of $6.3 \mathrm{ml} \cdot \mathrm{hr}^{-1}$ and that of lidocaine $6 \%$-buprenorphine at a rate of $2.1 \mathrm{ml} \cdot \mathrm{hr}^{-1}$ in combination with a fixed dose of buprenorphine for postoperative pain relief following upper abdominal surgery.

Although there has been some argument whether the efficacy of a local anaesthetic agent for extradural analgesia depends upon the volume of local anaesthetic or the dose of the agent, it is now considered that the efficacy is dose-dependent. Crawford ${ }^{11}$ compared extradural $30 \mathrm{ml}$ prilocaine $2 \%$ and $20 \mathrm{ml}$ prilocaine $3 \%$ (prilocaine $600 \mathrm{mg}$ ) for latency, duration, etc., and found that the two solutions were similar, and that $30 \mathrm{ml}$ prilocaine $2 \%$ produced greater muscle relaxation and more hypotension than did $20 \mathrm{ml}$ prilocaine $3 \%$. Erdemir et al. ${ }^{12}$ showed that $30 \mathrm{ml}$ lidocaine $1 \%$ produced levels of anaesthesia higher than those produced by $10 \mathrm{ml}$ lidocaine $3 \%$, and that the low-volume injections were accompanied by incomplete anaesthesia. Bromage et al. ${ }^{13}$ gave extradural blocks with either lidocaine in a concentration of $1 \%$ to $5 \%$, or tetracaine in a concentration of $0.1 \%$ to $0.5 \%$. The mass of drug required per spinal segment was found to be similar for the $2,3,4$, and $5 \%$ concentrations of lidocaine, and only the $1 \%$ 
solution behaved differently in that it spread further, and its requirement was about one-third less than that of the other concentrations. Bromage and colleagues observed a similar pattern with tetracaine. The $0.1 \%$ solution gave poor analgesia, while the $0.5 \%$ solution required more drug per spinal segment than did the other concentrations. They concluded that the volume of the drug was unimportant in determining spread, and that the concentration is unimportant in determining the intensity of block, but mass of the drug (that is the product of volume times concentration) is the important factor. Thorburn and Moir ${ }^{14}$ gave extradural analgesia to women in labour, using bupivacaine plain solution. They were randomly allocated to one of three groups: group A received $6-8 \mathrm{ml}$ of $0.5 \%$ solution, group B $10-14 \mathrm{ml}$ of $0.25 \%$ solution, and group C 6$8 \mathrm{ml}$ of $0.25 \%$ solution. The analgesia was most effective in group A, less effective in group B, and least effective in group $\mathrm{C}$, both during labour and at delivery. Motor block was most frequent and rapidly progressive in group A. The frequency of hypotension was similar among the three groups. Duggan et al. ${ }^{15}$ investigated the influences of dose, volume and concentration on the development of extradural blockade produced by low lumbar injection of bupivacainc. They gave one of three solutions: $10 \mathrm{ml} 0.75 \%(75 \mathrm{mg}), 15 \mathrm{ml} 0.5 \%(75 \mathrm{mg})$, and $15 \mathrm{ml} 0.75 \%(112.5 \mathrm{mg})$. The number of segments blocked at maximal extent of block was similar in each group. The larger dose of bupivacaine (112.5 $\mathrm{mg}$ ) produced the fastest onset of analgesia and longest duration of sensory block, and the smaller dose $(75 \mathrm{mg})$ in either $10 \mathrm{ml}(0.75 \%)$ or $15 \mathrm{ml}(0.5 \%)$ solution produced similar onset and duration. Their results showed that, with low lumbar injection of bupivacaine, the single most important factor was dose of drug. The results of the present study show that the postoperative pain relief effect of lidocaine, with a fixed dose of opioid, is also dose-dependent.

Thomson et al. ${ }^{16}$ recently examined whether, for equal fentanyl dosages, the extradural infusion of fentanyl at a low concentration $\left(5 \mu \mathrm{g} \cdot \mathrm{ml}^{-1}\right)$ and a high infusion rate provided better analgesia after thoracotomy than that at a high $\left(10 \mu \mathrm{g} \cdot \mathrm{ml}^{-1}\right)$ concentration infused at a rate half that used for the $5 \mu \mathrm{g} \cdot \mathrm{ml}^{-1}$ concentration. However, their study did not demonstrate that, for the same total fentanyl dose, a concentration $5 \mu \mathrm{g} \cdot \mathrm{ml}^{-1}$ infused at a higher rate provided a consistent statistically significant improvement in analgesia overall or in the rostal portion of the incision compared to $10 \mu \mathrm{g} \cdot \mathrm{ml}^{-1}$ infused at half the rate. In our study, we chose buprenorphine as the opioid, which was infused at a low concentration at higher infusion rate and a high concentration at a lower infusion rate. The difference in the concentration/infusion rate of buprenorphine in our two groups may not be important, in light of the findings of Thomson et al. described above. ${ }^{16}$

In our study, the arterial blood pressure in both groups was stable following surgery and no medication was needed for hypotension. No subjective side effects due to possible lidocaine overdose were seen; the use of this drug produced no safety concerns, at least up to $23 \mathrm{~h}$ postoperation. Takaya et al. ${ }^{17}$ measured the arterial serum lidocaine level to determine whether the serum lidocaine level during the continuous extradural block correlates with the preoperative liver function, i.e., serum albumin concentration, serum cholinesterase (ChE) activity, glutamic pyruvic transaminase (GPT) and indocyanine green retention rate (ICG $\mathrm{R}_{15}$ ). The results revealed that the lower the serum albumin level and $\mathrm{ChE}$ activity were, the higher the serum lidocaine level, and that it had no correlation with GPT and ICG $\mathrm{R}_{15}$. They concluded that any patient with hypoalbuminaemia and low serum $\mathrm{ChE}$ activity might have higher blood lidocaine levels during continuous extradural block. A high rate extradural administration may induce lidocaine toxicity. To prevent this, the patients's hypoalbuminaemia and low serum ChE activity must be considered.

There are reports that high concentrations of lidocaine can be used safely. Bromage ${ }^{13,18}$ chose lidocaine $5 \%$ for an extradural block. Fukui and Kamiyama ${ }^{19}$ used lidocaine $6 \%$ for an extradural block in aged patients in safe and no neurotoxity was found. However, we did not find that the $6 \%$ group had better analgesia than those of the $2 \%$ group in this study. Thus, we recommend the use of lidocaine $2 \%$ rather than lidocaine $6 \%$.

The possible side effects of extradural buprenorphine include nausea, vomiting, dizziness and drowsiness. ${ }^{2-4,20-28}$ In this study, there were no major adverse effects, such as respiratory depression. Ochi and $\mathrm{Arai}^{24}$ showed that the incidence of emetic complications after extradural buprenorphine for postoperative analgesia was related to the incidence of postoperative pain, and that the successful treatment of postoperative pain reduced the incidence of emetic complications. There were few emetic side effects in our study. One of the reasons for this may be due to the successful postoperative pain relief.

In summary, there was no difference between the continuous extradural infusion of lidocaine $2 \%$ buprenorphine at a rate of $6.3 \mathrm{ml} \cdot \mathrm{hr}^{-1}$ and that of lidocaine $6 \%$-buprenorphine at a rate of $2.1 \mathrm{ml} \cdot \mathrm{hr}^{-1}$ for postoperative pain relief following upper abdominal surgery, and that both two doses were safe, at least up to 24 hr postoperation. However, we could not find that the $6 \%$ group achieved better results than the $2 \%$ group in this study, and we recommend the use of lidocaine $2 \%$ rather than lidocaine $6 \%$. 


\section{References}

1 Burgess FW, Anderson DM, Colonna D, Cavanaugh DG. Thoracic epidural analgesia with bupivacaine and fentanyl for postoperative thoracotomy pain. J Cardiothorac Vasc Anesth 1994; 8: 420-4.

2 Hayashi $H$, Kanob T, Inoue $T$, Nishiuchi T, Tamura $H$, Takeda $K$. Postoperative pain relief by continuous epidural infusion: a comparison of three solutions. (Japanese) Masui 1993; 42: 1477-83.

3 Hirabayashi $\Upsilon$, Saitoh K, Fukuda H, Mitsubata $H$, Shimizu $R$. Continuous epidural infusion of bupivacaine and buprenorphine for postoperative pain relief. (Japanese) Masui 1992; 41: 1875-80.

4 Obtaka K, Matsumoto S, Mitsubata H, Yabe M. The effect of continuous epidural infusion of combination of $1 \%$ mepivacaine and buprenorphine for post-operative pain relief. (Japanese) Masui 1991; 40: 942-8.

5 Uchida H, Takasaki M, Sakura S, Dehara $K$, Tsuji $M$, Kosaka $Y$. Continuous epidural infusion of bupivacaine and morphine for postoperative pain relief. (Japanese) Masui 1990; 39: 237-42.

6 Huskisson EC. Measurement of pain. Lancet 1974; 2: 1127-31.

7 Scott J, Huskisson EC. Graphic representation of pain. Pain 1976; 2: 175-84.

8 Torda TA, Pybus DA. Extradural administration of morphine and bupivacaine. A controlled comparison. Br J Anaesth 1984; 56: 141-6.

9 Bertol E, Mari F, Torracca F. Comparison of lidocaine by fluorescence polarization immunoassay, enzyme immunoassay, and high resolution gas chromatography. J Anal Toxicol 1987; 11: 122-4.

10 Wajima Z, Shitara T, Ishikawa G, Kaneko K, Inoue T, Ogawa $R$. Analgesia after upper abdominal surgery using extradural administration of a fixed dose of buprenorphine in combination with lignocaine given at two infusion rates: a comparative study. Acta Anaesthesiol Scand 1997; 41: 1061-5.

11 Crawford $O B$. Comparative evaluation in peridural anesthesia of lidocaine, mepivacaine and L-67, a new local anesthetic agent. Anesthesiology 1964; 25: 321-9.

12 Erdemir $H A$, Soper $L E$, Sweet $R B$. Studies of factors affecting peridural anesthesia. Anesth Analg 1965; 44: 400-4.

13 Bromage $P R$. Mechanism of action of extradural analgesia. Br J Anaesth 1975; 47: 199-211.

14 Thorburn J, Moir DD. Extradural analgesia: the influence of volume and concentration of bupivacaine on the mode of delivery, analgesic efficacy and motor block. Br J Anaesth 1981; 53: 933-9.

15 Duggan J, Bowler GMR, McClure JH, Wildsmith JAW. Extradural block with bupivacaine: influence of dose, volume, concentration and patient characteristics. Br J Anaesth 1988; 61: 324-31.
16 Thomson CA, Becker DR, Messick JM Jr, et al. Analgesia after thoracotomy: effects of epidural fentanyl concentration/infusion rate. Anesth Analg 1995; 81: 973-81.

17 Takaya $T$, Takigachi $M$, Yamasaki $\Upsilon$. Effect of preoperative liver function on serum lidocaine level during continuous epidural block. (Japanese) Masui 1994; 43: 650-6.

18 Bromage PR. The spread and site of action of local anesthetic agents in the peridural space. Int Anesth Clin 1962; 2: 543-63.

19 Fukui S, Kamiyama $Y$. Advantage of epidural block with high-concentration lidocaine $(6 \%)$ in aged patients.

(Japanese) Journal of Japan Society for Clinical Anesthesia 1993; 13: 451-8.

20 Hirabayashi $\Upsilon$, Mitsubata $H$, Shimizu $R$, et al. Continuous epidural buprenorphine for postoperative pain relief in upper abdominal surgery. (Japanese) Masui 1994; 43: 988-92.

21 Shiraishi $Y$, Sakai S, Yokoyama J, et al. The plasma concentration of buprenorphine during its continuous epidural infusion after catheterization at different vertebral levels. (Japanese) Masui 1993; 42: 371-5.

22 Hayashi $H$, Nishiuchi T, Tamura $H$, Takeda $K$. Comparison of buprenorphine and fentanyl for postoperative pain relief by continuous epidural infusion. (Japanese) Masui 1993; 42: 1763-8.

23 Hirabayashi $Y$, Fukuda $H$, Saitou $K$, et al. Postoperative pain relief by continuous epidural infusion of bupivacaine and buprenorphine. (Japanese) Masui 1992; 41: 1580-4.

24 Ochi $G$, Arai $T$. Incidence of nausea and vomiting associated with epidural buprenorphine for postoperative analgesia. An analysis in relation to its analgesic effect. J Anesth 1991; 5: 412-5.

25 Carl $P$, Crawford ME, Ravlo O, Bach V. Longterm treatment with epidural opioids. A retrospective study comprising 150 patients treated with morphine chloride and buprenorphine. Anaesthesia 1986; 41: 32-8.

26 Gundersen RY, Andersen R. Narverud G. Postoperative pain relief with high-dose epidural buprenorphine: a double-blind study. Acta Anaesthesiol Scand 1986; 30: 664-7.

27 Lanz E, Simko G. Theiss D, Glocke $M H$. Epidural buprenorphine: a double-blind study of postoperative analgesia and side effects. Anesth Analg 1984; 63: 593-8.

28 Miwa $\Upsilon$, Yoneyama E, Fukushima K. Epidural administered buprenorphine in the perioperative period. Can J Anaesth 1996; 43: 907-13. 